\title{
8
}
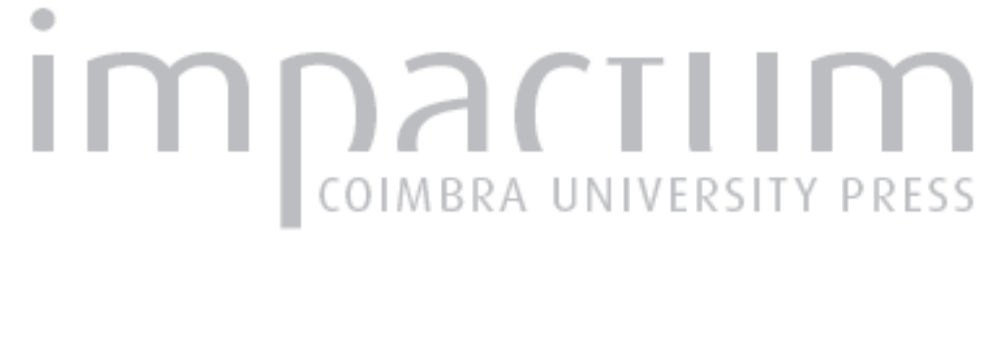

\section{Fernando Pessoa (1888-1935): os rostos plurais}

Publicado por: Imprensa da Universidade de Coimbra

URL

persistente:

URI:http://hdl.handle.net/10316.2/43041

DOI:

DOI:https://doi.org/10.14195/1647-8436_46_47_19

Accessed : $\quad 26-A p r-2023$ 00:37:40

A navegação consulta e descarregamento dos títulos inseridos nas Bibliotecas Digitais UC Digitalis, UC Pombalina e UC Impactum, pressupõem a aceitação plena e sem reservas dos Termos e Condições de Uso destas Bibliotecas Digitais, disponíveis em https://digitalis.uc.pt/pt-pt/termos.

Conforme exposto nos referidos Termos e Condições de Uso, o descarregamento de títulos de acesso restrito requer uma licença válida de autorização devendo o utilizador aceder ao(s) documento(s) a partir de um endereço de IP da instituição detentora da supramencionada licença.

Ao utilizador é apenas permitido o descarregamento para uso pessoal, pelo que o emprego do(s) título(s) descarregado(s) para outro fim, designadamente comercial, carece de autorização do respetivo autor ou editor da obra.

Na medida em que todas as obras da UC Digitalis se encontram protegidas pelo Código do Direito de Autor e Direitos Conexos e demais legislação aplicável, toda a cópia, parcial ou total, deste documento, nos casos em que é legalmente admitida, deverá conter ou fazer-se acompanhar por este aviso. 


\section{BOLETIM DA \\ BIBLIOTECA GERAL DA UNIVERSIDADE DE COIMBRA}

VOL. 46/47 (2015/2016)

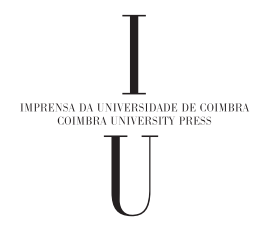




\section{Fernando Pessoa (1888-1935) : os rostos plurais}

\section{Sala do Catálogo, de 28 de setembro a 4 de dezembro de 2015}

Biblioteca Joanina, de 15 de dezembro de 2015 a 31 de janeiro de 2016

PESSOA, Fernando, 1888-1935

Antinous: a poem. Lisbon : Monteiro \& C., 1918.

RB-3-35

35 sonnets. Lisbon : Monteiro \& C., 1918.

RB-3-34

English poems. Lisbon : Olisipo, 1921.

RB-3-35 A

O interregno: defeza e justificação da dictadura militar em Portugal. Lisboa : Núcleo de Acção Nacional, 1928.

5-46-7

Poesias. [Nota explicativa de João Gaspar Simões, Luiz de Montalvor]. 2a ed. Lisboa : Ática, 1942.

5-33-29

Páginas de doutrina estética. Selecção, pref. e notas de Jorge de Sena. Lisboa : Inquérito, imp. 1946.

5-40-23 
O preconceito da ordem; com uma nota de Álvaro Bordalo. Porto : [s. n.], [1950?].

5-43-29

Poesias de Álvaro de Campos. Lisboa : Ática, 1951.

5-44-33

Análise da vida mental portuguesa : ensaios críticos. $1^{\text {a }}$ ed. Porto : Edições Cultura, [D. L. 1951?].

$5-45-3$

Apreciações literárias : bosquejos e esquemas críticos. Porto : Editorial Cultura, [1951?].

$5-45-3$

A nossa crise: seus aspectos político, moral e intelectual; com uma nota de Ávaro Bordalo. Porto : [s. n.], [1951?].

5-44-5

Ultimatum de Álvaro de Campos sensacionista. Porto : Editorial Cultura, [1951?].

$5-45-22$

Crónicas intemporais. Selecção e comentários de Petrus. [S. I.] : Centro Editorial Português, [1952?].

$5-42-13$

Poemas de Alberto Caeiro. 2a ed. Lisboa : Edições Ática, 1952.

$5-46-18$

Poemas dramáticos. Lisboa : Ática, 1952.

$5-45-21$

Poemas ocultistas. Sel. e glosa de Petrus; [des. de Manuel Lapa]. [S.I. : s.n., D.L. 1952].

$5-46-2$ 
Regresso ao sebastianismo : Fernando Pessoa e outros. Porto : [s.n., 1952?]. 5-46-2

Elogio da indisciplina ; [Poemas insubmissos]. [Porto] : Centro Editorial Português, [1953?] (Porto : Tip. J. R. Gonçalves).

$5-46-32$

Poemas inéditos destinados ao n 3 do "Orpheu" ; Pref. de Adolfo Casais Monteiro ; [retrato inédito de Rodríguez Castañé]. Lisboa : Inquérito, 1953.

Ex. $n^{\circ} 60$ de uma tir. esp. de 60 exs., numerados e rubricados pelo prefaciador .

5-48-17

Ensaios políticos : ideias para a reforma da política portuguesa. Porto : C. E. P., [1954?].

5-10-19

Poesias inéditas : 1930-1935. Lisboa : Ática, imp. 1955.

5-39-3

Distância constelada : [álbum de poesias esparsas]. Porto : Parnaso, [1955?]. 5-44-5

Poesias inéditas : 1919-1930. Lisboa : Ática, imp. 1956.

5-54-3-30

Exórdio em prol da filantropia e da educação física: páginas desconhecidas.

[Des. de Manuel Lapa]. Porto : Editorial Cultura, [1956?].

5-23-37

Cartas de Fernando Pessoa a João Gaspar Simões. Int., apêndice e notas do destinatário. Lisboa: Publicações Europa-América, imp. 1957.

5-50-49-24 
Fernando Pessoa : poesia . [Apresent.] por Adolfo Casais Monteiro. Rio de Janeiro : Livraria Agir, 1957.

5-66-23

Apologia do paganismo. Porto : Editorial Cultura, [1957?].

5-52-25-28

A nova poesia portuguesa. Pref. de Álvaro Ribeiro. $2^{\text {a }}$ ed. Lisboa : Inquérito, [1960?].

5-44-59

O banqueiro anarquista e outros contos de raciocínio. Antologia organizada e prefaciada por Fernando Luso Soares. Lisboa : Editora Lux, 1964. 5-42-22

Almas e estrelas : Horas espirituais. Porto : Arte e Cultura, [1966?].

5-30-7

O banqueiro anarquista. Porto : Arte \& Cultura, 1966.

5-12-35-210

Páginas de estética e de teoria e crítica literárias. Textos estabelecidos e pref. por Georg Rudolf Lind e Jacinto do Prado Coelho ; trad. dos textos ingleses por Jorge Rosa. Lisboa : Ática, [1967?].

5-47-1

Textos para dirigentes de empresas. Lisboa : Cinevoz, 1969.

$5-7-31-60$

35 sonnets : English poems $=35$ sonetos : poemas ingleses. Versão portuguesa de Fernando Dias. Lisboa : F. Dias, 1975.

5-33-40-40

Barbearias. Fot. Alexandre Delgado O'Neill. 1ª ed. Lisboa : Rolim, 1986. 5-11-41-71 
Antinoo. Trad. Luís Nogueira. Lisboa : Fenda, imp. 1988.

6-40-34-164

Antologia: a maçonaria vista por Fernando Pessoa e Norton de Matos. $1^{\text {a }}$ reimp. fac-simil. [S. I.] : José Ribeiro, 1988.

5-33-74-121

A hora do diabo. Posfácio, pesquisa, transcrição e organização de texto de Teresa Rita Lopes. Lisboa : Rolim, 1988.

6-47-33-52

O guardador de rebanhos. II. Pedro Proença. Colares : Colares Editora, D.L. 1992.

6-42-17-39

Poesias de Álvaro de Campos. Mem Martins : Publicações Europa-América, 1997.

6-47-28-39

Como organizar Portugal. Lisboa : Nova Ática, imp. 2006.

10-(1)-10-8-4

A essência do comércio e outros textos de teoria económica. Lisboa : Nova Ática, D.L. 2006.

$10-(1)-1-1-53$

Aviso por causa da moral e outros textos de intervenção de Álvaro de Campos. Lisboa : Nova Ática, D.L. 2007.

9-(1)-9-20-75

Mensagem. Ed. facsímil. [S.I. : s.n.], D.L. 2007.

9-(1)-4-48-59

Um grande português ou a origem do conto do vigário. Lisboa : Nova Ática, imp. 2007.

10-(1)-10-8-2 
A imortalidade. Coimbra : Alma Azul, 2009.

6-38-9-59

A demonstração do indemonstrável. Ed., posf. e notas Jorge Uribe ; trad.

Pedro Sepúlveda ; rev. filológica Jerónimo Pizarro. Lisboa : Ática, 2011. 10-(1)-4-2-15

\section{Colaboração em publicações periódicas}

PESSOA, Fernando, 1888-1935

A nova poesia portugueza sociologicamente considerada. A Águia. Porto.

2 : 4 (abr. 1912) 101-107.

9-(3)-20-36

Impressões do crepúsculo. A Renascença. Lisboa. 1 (fev. 1914) 11. 10-11-7-7

O marinheiro: drama estático em um quadro. Orpheu. Reedição. Lisboa. 1 : 1 (jan./mar. 1915) 33-53.

10-17-18-7

O banqueiro anarchista. Contemporanea. Ed. fac-simil. Lisboa. 1 : 1/3 (maio/ jul. 1922) 5-21.

10-9-18

Athena. Athena : revista de arte. Ed. fac-simil. Lisboa. 1 : 1 (out. 1924) 5-8. 10-1-15-9

A essência do comércio. Revista de Comércio e Contabilidade. Lisboa. V1 : 1 (jan. 1926) 7-11.

$10-1-15-2$ 
Do Livro do Desassossego, composto por Bernardo Soares, ajudante de guarda-livros na cidade de Lisboa. Presença. Ed. fac-simil. Lisboa. 2 : 34 (nov./fev. 1931/1932) 8.

10-3-18-10

\section{Bibliografia passiva}

LANCASTRE, Maria José de

Fernando Pessoa: immagini della su vita. Milano : Adelphi, imp. 1988.

7-75-14-39

Fernando Pessoa : uma fotobiografia. Lisboa : Quetzal, 1996.

5-56-30-9

Fernando Pessoa: uma fotobiografia. $3^{\mathrm{a}}$ ed. Lisboa : INMC, Centro de Estudos Pessoanos, imp. 1984.

$5-22-29-30$

NOGUEIRA, Manuela

Fernando Pessoa: imagens de uma vida. 2a ed. Lisboa : Assírio e Alvim, 2005. 8-(2)-25-15-56

ZENITH, Richard

Fotobiografias século XX : Fernando Pessoa. Lisboa : Círculo de Leitores, D.L. 2008.

8-(2)-26-30-34 